\title{
A MOVING SUBGRID MODEL FOR SIMULATION OF REFLOOD HEAT TRANSFER
}

\author{
Cesare Frepoli \\ Westinghouse Electric Co. \\ P.O. Box 355, Monroeville, PA
}

\author{
John H. Mahaffy \\ Penns State University \\ 237 Reber Bldg., University Park, PA
}

\author{
Lawrence E. Hochreiter \\ Penn State University \\ 237 Reber Bldg., University Park, PA
}

\begin{abstract}
In the quench front and froth region the thermal-hydraulic parameters experience a sharp axial variation. The heat transfer regime changes from single-phase liquid, to nucleate boiling, to transition boiling and finally to film boiling in a small axial distance.

One of the major limitations of all the current best-estimate codes is that a relatively coarse is used to solve the complex fluid flow and heat transfer problem in proximity of the quench front of a reactor core during reflood. The use of a fine axial mesh for the entire core becomes prohibitive because of the large computational costs involved. Moreover as the mesh size decreases, the standard numerical methods based on a semiimplicit scheme, tend to become unstable.

A sub-grid model was developed to resolve the complex thermal-hydraulic problem at the quench front and froth region. The model is a Fine Hydraulic Moving Grid that overlies a coarse Eulerian mesh in the proximity of the quench front and froth region. The fine mesh moves in the core and follows the quench front as it advances in the core while the rods cool and quench. The Fine Hydraulic Moving Grid (FHMG) software package was developed and implemented into the COBRA-TF computer code. This paper presents the model and discusses preliminary results obtained with the COBRA-TF/FHMG computer code.
\end{abstract}

\section{INTRODUCTION}

Effective cooling from the core is calculated to be lost during the end of the blowdown phase of Large Break LOCA accident. The reactor core experiences an almost adiabatic heatup during this period. As the cooling water enters the core, it contacts the hot rods and begins to reestablish effective core cooling. It is during this period that the peak cladding temperature is reached. High flow rates of superheated vapor result from the steam generated as the rods quench. Vapor velocities are usually high enough to entrain significant fraction of liquid in the form of drops.

The best-estimate calculations indicate that for nearly all the PWR designs the peak cladding temperatures are reached during the reflood portion of the transient at low pressures, typically one to three bars.

During the reflood the thermal-hydraulic phenomena that dominates is Dispersed Flow Film Boiling. The heat transfer is a two-step process, with heat being transferred from the wall to the vapor and interfacial heat transfer occurring between the entrained liquid and the superheated vapor which establishes the vapor temperature. The droplet are entrained in the froth region above the quench front.

The major uncertainties in predicting the heat transfer during core reflood is the modeling of the complex phenomena occurring at the quench front. In the quench region the thermalhydraulic parameters experience a sharp axial variation. The heat transfer regime changes from single-phase liquid, to nucleate boiling, to transition boiling and finally to film boiling in a small axial distance. A large amount of steam is generated as the rod quenches and the resulting steam flow entrains liquid droplets.

At the quench front and froth region, there are several competing phenomena which ultimately determine the heat transfer during reflood. Each of the individual process need to be accurately predicted by the computer codes while compensating errors need to be minimized to reduce the code uncertainty. 
There are several best estimate computer codes, which are used to simulate the core reflood conditions for reactor safety analysis. The most important are the versions of TRAC [1], RELAP5 [2], COBRA-TF [3,4] and CATHARE [5,6,7]. Among them the COBRA-TF safety analysis code has several features that are unique in representing the key thermal-hydraulic processes involved during a reflood transient. The most important is the three-field treatment of the two-phase flow. The liquid phase is split in two fields with a continuous liquid field and a separate droplet field. Three separate momentum equations are solved for the vapor phase, the continuous liquid field and the entrained droplet field. Entrainment and deentrainment models are included in the code. The advantage of using a three-field approach, when modeling a core reflood, are that the droplet entrainment and de-entrainment mechanisms, the effect of the droplets in de-superheating the steam, the droplet breakup at the spacer grids and other drop related processes are explicitly simulated in the code.

The reflood model of COBRA-TF as well as other codes (RELAP5, TRAC, CATHARE) uses an axial fine mesh zone across the quench front for the solution of the axial heat conduction in the fuel rods. However one of the major limitations of all the best-estimate codes are the use of a relative coarse mesh for the solution of the complex fluid flow at the quench front region in a reactor core during reflood.

Computational costs, numerical stability issues and the lack of detailed experimental data historically dictated the use of a coarse mesh. The hydraulic mesh size typically used in a reflood calculation is about $30 \mathrm{~cm}$. This mesh is accurate enough to capture large-scale phenomena but it becomes too coarse if compared with the large variations of the void fraction and other parameters across the quench region. This represents a limitation when better physical model describing the phenomena in proximity of the quench front and froth region needs to be implemented. In fact it is believed [8] that only improving the understanding of physical processes at the most fundamental level, and integrating this understanding into the computation method we can reduce the uncertainty of current computational models.

Results from noding sensitivity studies using COBRA-TF [9] indicated that the hydraulic mesh size does have an effect on the calculated peak cladding temperature. The effect on the Peak Clad Temperature (PCT) can be very small, but the node size effect on other parameters such as the vapor temperature, the quench front velocity and the entrainment can be significant. More important the noding sensitivity studies showed that the current computational method is not suitable for small cell sizes.

Another major problem in developing a fine hydraulic mesh for the quench front and froth region is that the quench front is moving in the domain during reflood. Therefore the fine mesh needs to be extended to the entire domain (the core). This limitation comes from the Lagrangian' nature of the reflood process while the computational model is Eulerian.
The objective of this work was to develop a hydraulic 'subgrid' model with a fine moving mesh which overlies the coarse Eulerian hydraulic mesh for modeling reflood heat transfer. The idea is to model the quench front region with a local fine mesh such that the key thermal-hydraulic processes can be resolved on a much smaller space scale than the current models. A new model has been developed which is called Fine Hydraulic Moving Grid (FHMG). This module follows the quench front as it advances into the core during reflood. The module is coupled with the coarse Eulerian mesh, which is still used to model the entire core. By solving locally the small-scale fluid flow and heat transfer features, the FHMG improves the prediction of important local phenomena such as the entrainment and local heat transfer. These local parameters are integrated over the fine subgrid and used in the form of source terms for the coarse Eulerian mesh to obtain the solution of the large-scale core behavior. The aim is to reduce the compensating errors which arises when the thermal-hydraulic details of the quench front region are lost in the lumping process of a coarse mesh.

\section{DESCRIPTION OF THE REFLOOD MODEL}

The FHMG computational module is characterized by a local fine hydraulic mesh or 'subgrid' which follows the quench front as it moves into the core. The fine mesh module is used to solve the coupled two-phase flow and heat transfer problem in the quench front and froth region with much greater detail than the current model. The moving sub-grid 'slides' over the Eulerian mesh of the system code that is used to simulate the reflood as shown in Figure 1. The primary output of the FHMG module is an improved estimate of the source terms for the entrainment/de-entrainment, vapor generation and local wall heat transfer. The source terms calculated with the sub-grid replace the source term in the governing equation of the coarse Eulerian mesh in the region of the quench front and froth region.

The FHMG is conceived as a 'stand-alone' software package and in general it can be implemented in any system code provided the specific interface is designed. The FHMG module has been incorporated into the COBRA-TF code. The new version of the code was called COBRA-TF/FHMG and has been tested by comparing the code prediction to data obtained from reflood experiments.

The current implementation of the FHMG module is a simple explicit coupling where the FHMG receives the boundary conditions from the system code (COBRA-TF) and solves the coupled hydraulic / heat transfer problem at the quench front and froth region. The improved source terms generated with the fine moving mesh are then integrated in space and used by the coarse Eulerian mesh to obtain the global solution.

The hydraulic model is approximated as one-dimensional. The assumption is that the three-dimensional flow occurs in the core on a larger space-scale than the size of the subgrid. The three-dimensional flow in the core is still calculated by the system code while the FHMG is used to resolve the flow on the 
'small' space-scale (subgrid) where the flow can be assumed as one-dimensional.

The one-dimensional two-phase flow model is based on the three-field approach where the liquid phase is divided in a continuous field (the film) and a droplets field. The model solves the thermal-hydraulics in a region that spans across the quench front and include the entire froth region above the quench front.

The FHMG model is based on a fully-implicit scheme for both heat conduction and fluid flow as well as for the coupling between the local wall-to-fluid heat transfer and fluid flow. This allows a stable solution with a relatively large time step even for very small node sizes (of the order of $1 \mathrm{~cm}$ ). At this point, the coupling between the solution at the subgrid level (FHMG) and the coarse mesh (Eulerian code, i.e. COBRA-TF) is explicit but further work will consider a more implicit coupling.

The three-field formulation used in the FHMG module is a straightforward extension of the two-fluid single-pressure model. The fields included are vapor, continuous liquid, and entrained liquid. As a result the one-dimensional fluid flow is governed by eight equations: three mass conservation equations, two energy equations and three momentum conservation equations. The use of two energy equations instead of three is justified by assuming that the enthalpy of the continuous liquid field is equal to the enthalpy of the dispersed liquid field. The three continuity equations are:

$$
\begin{gathered}
\frac{\partial\left(\alpha_{v} \rho_{v}\right)}{\partial t}=-\frac{\partial\left(\alpha_{v} \rho_{v} u_{v}\right)}{\partial x}+\Gamma^{\prime \prime \prime} \\
\frac{\partial\left(\alpha_{l} \rho_{l}\right)}{\partial t}=-\frac{\partial\left(\alpha_{l} \rho_{l} u_{l}\right)}{\partial x}-(1-\eta) \Gamma^{\prime \prime \prime}+S_{D}^{\prime \prime \prime}-S_{E}^{\prime \prime \prime} \\
\frac{\partial\left(\alpha_{e} \rho_{l}\right)}{\partial t}=-\frac{\partial\left(\alpha_{e} \rho_{l} u_{e}\right)}{\partial x}-\eta \Gamma^{\prime \prime \prime}-S_{D}^{\prime \prime \prime}+S_{E}^{\prime \prime \prime}
\end{gathered}
$$

The coefficient $\eta$ in the previous equations is the fraction of vapor generated by droplets. The two conservation of energy equations are:

$$
\begin{aligned}
& \frac{\partial\left(\alpha_{v} \rho_{v} h_{v}\right)}{\partial t}=-\frac{\partial\left(\alpha_{v} \rho_{v} u_{v} h_{v}\right)}{\partial x}+\Gamma^{\prime \prime \prime} h_{g}+q_{i v}+Q_{w v}+\alpha_{v} \frac{\partial P}{\partial t} \\
& \frac{\partial\left(\left(1-\alpha_{v}\right) \rho_{l v} h_{l}\right)}{\partial t}=-\frac{\partial\left(\left(\alpha_{l} u_{l}+\alpha_{e} u_{e}\right) \rho_{l} h_{l}\right)}{\partial x}-\Gamma^{\prime \prime \prime} h_{f} \\
& +q_{i l}+Q_{w l}+\left(1-\alpha_{v}\right) \frac{\partial P}{\partial t}
\end{aligned}
$$

The three momentum conservation equations are written in the non-conservative form as:

$$
\begin{gathered}
\alpha_{v} \rho_{v} \frac{\partial u_{v}}{\partial t}=-\alpha_{v} \rho_{v} u_{v} \frac{\partial u_{v}}{\partial x}-\alpha_{v} \rho_{v} g-\alpha_{v} \frac{\partial P}{\partial x} \\
-\tau_{w}-\tau_{i, v l}-\tau_{i, v e}-\Gamma_{E}^{\prime \prime \prime}\left(u_{v}-(1-\eta) u_{l}-\eta u_{e}\right) \\
\alpha_{l} \rho_{l} \frac{\partial u_{l}}{\partial t}=-\alpha_{l} \rho_{l} u_{l} \frac{\partial u_{l}}{\partial x}-\alpha_{l} \rho_{l} g-\alpha_{l} \frac{\partial P}{\partial x} \\
-\tau_{w l}+\tau_{i, v l}+(1-\eta) \Gamma_{C}^{\prime \prime \prime}\left(u_{v}-u_{l}\right)+S_{D}^{\prime \prime \prime}\left(u_{e}-u_{l}\right) \\
\alpha_{e} \rho_{l} \frac{\partial u_{e}}{\partial t}=-\alpha_{e} \rho_{l} u_{e} \frac{\partial u_{e}}{\partial x}-\alpha_{e} \rho_{l} g-\alpha_{e} \frac{\partial P}{\partial x} \\
+\tau_{i, v e}+\eta \Gamma_{C}^{\prime \prime \prime}\left(u_{v}-u_{e}\right)-S_{E}^{\prime \prime \prime}\left(u_{e}-u_{l}\right)
\end{gathered}
$$

The models and correlations, which are used to define the closure relationships for the fluid flow equations, are based on the COBRA-TF heat transfer and fluid packages.

The finite difference equations are obtained from the typical staggered-difference scheme where the velocities are obtained at the mesh cell faces and the state variables, such as pressure, density, enthalpy, and void fraction, are obtained at the cell center.

In addition to the fluid flow equation, for the droplet field an interfacial area transport equation is used to determine the interfacial area of the liquid dispersed field:

$$
\frac{\partial A_{i, d}^{\prime \prime \prime}}{\partial t}+\frac{\partial}{\partial x}\left(A_{i, d}^{\prime \prime \prime} u_{e}\right)=\left(\frac{\partial A_{i, d}^{\prime \prime \prime}}{\partial t}\right)_{E}+\left(\frac{\partial A_{i, d}^{\prime \prime \prime}}{\partial t}\right)_{\Gamma}
$$

The equation (9) states that the total time derivative of the interfacial area concentration is equal to the sum of two contributions: the change of interfacial area due to the entrainment and the change due to the evaporation.

The finite difference equations are based on a fully implicit scheme. The Finite Volume equations are obtained by integrating the conservation (PDE) equations over the moving control volume. The mesh is moving with the quench front at the velocity $u_{\text {grid }}$ and the equations need to be integrated accordingly. For example, if we consider the vapor continuity equation:

$$
\frac{\partial\left(\alpha_{v} \rho_{v}\right)}{\partial t}=-\frac{\partial\left(\alpha_{v} \rho_{v} u_{v}\right)}{\partial x}+\Gamma^{\prime \prime \prime}
$$

By integrating this equation over a control volume whose boundaries move with time, i.e. from $x_{1}(t)$ to $x_{2}(t)$, we get: 


$$
\int_{x_{1}(t)}^{x_{2}(t)} \frac{\partial\left(\alpha_{v} \rho_{v}\right)}{\partial t} d x+\int_{x_{1}(t)}^{x_{2}(t)} \frac{\partial\left(\alpha_{v} \rho_{v} u_{v}\right)}{\partial x} d x=\int_{x_{1}(t)}^{x_{2}(t)} \Gamma^{\prime \prime \prime} d x
$$

The Leibniz rule applied to a generic function $\Phi$ states the following:

$$
\int_{x_{1}(t)}^{x_{2}(t)} \frac{\partial \Phi}{\partial t} d x=\frac{d}{d t} \int_{x_{1}(t)}^{x_{2}(t)} \Phi d x-\left[\Phi_{2} \frac{d x_{2}}{d t}-\Phi_{1} \frac{d x_{1}}{d t}\right]
$$

If the grid is not deforming, but it is only subjected to a translational motion with velocity $\mathrm{u}_{\text {grid }}$ we have:

$$
\frac{d x_{2}}{d t}=\frac{d x_{1}}{d t}=u_{\text {grid }}
$$

and

$$
\int_{x_{1}(t)}^{x_{2}(t)} \frac{\partial \Phi}{\partial t} d x=\frac{d}{d t} \int_{x_{1}(t)}^{x_{2}(t)} \Phi d x-\left[\Phi_{2}-\Phi_{1}\right] u_{\text {grid }}
$$

For instance, applying this rule to the vapor mass conservation equation (Eq. 10) we obtain:

$$
\begin{aligned}
& \frac{d}{d t} \int_{x_{1}(t)}^{x_{2}(t)}\left(\alpha_{v} \rho_{v}\right) d x+ \\
& {\left[\left(\alpha_{v} \rho_{v}\left(u_{v}-u_{\text {grid }}\right)\right)_{2}-\left(\alpha_{v} \rho_{v}\left(u_{v}-u_{\text {grid }}\right)\right)_{1}\right]=\int_{x_{1}(t)}^{x_{2}(t)} \Gamma^{\prime \prime \prime} d x}
\end{aligned}
$$

Therefore the integration of the equations over a moving grid produces additional terms in the discrete equations which contains the grid velocity as an additional parameter. For all the equations this results in modified convective terms. In addition the energy contain some additional pressure terms which result from the integration of the pressure time derivatives.

A two-dimensional (radial and axial) heat conduction model is used to calculate the heat transfer from the quenching rods to the fluid. The axial mesh spacing used for the rods corresponds to the hydraulic mesh. Similarly to the fluid equations, since the mesh is moving during the calculation, the heat conduction equation includes additional terms containing the velocity of the mesh $u_{\text {grid. }}$ These terms account for the heat flux, which is 'convected' because of the grid motion.

The heat conduction equation is integrated using a Finite Volume Method (FVM). The solution of the heat conduction is based on the Alternate Direction Implicit (ADI) method [13]. This is a two-step method where the solution is obtained by solving two half time steps. The first step is explicit in the radial direction and implicit in the axial direction. The second step is implicit in the radial direction and explicit in the axial direction. This technique offers several advantages: at first the method is unconditionally stable; second the solution matrices are threediagonal and third the heat transfer can be implicitly coupled with the fluid flow solution with limited effort.

The velocity $u_{\text {grid }}$ is obtained with an additional equation obtained by solving the heat conduction problem at the quench front location. The equation is based on the condition that at the quench front location the wall temperature is known and it is equal at the critical heat flux temperature $\left(\mathrm{T}_{\mathrm{CHF}}\right)$

The previous system of non-linear equations is solved with the Newton iterative method [14]. The evaluation of the Jacobian based on analytical derivation can become cumbersome in this case and therefore the coefficients of the Jacobian matrix are evaluated numerically with a perturbation technique. The partial derivatives are approximated as follows:

$$
\frac{\partial f_{j}}{\partial x_{i}}=\frac{f_{j}\left(x_{1}, x_{2}, \ldots, x_{i}+\delta x_{i}, \ldots, x_{n}\right)-f_{j}\left(x_{1}, x_{2}, \ldots, x_{i}, \ldots, x_{n}\right)}{\delta x_{i}}
$$

where $\delta x_{i}$ is a small perturbation to the independent variable $x_{i}$. Time step size is adjusted automatically such that the convergence can be achieved in two-three iterations.

The FHMG module was finally implemented in the COBRATF computer code. The coupling is explicit and the new code version is called COBRA-TF/FHMG. The FHMG module calculates the source terms (entrainment, de-entrainment, local wall-to-fluid heat transfer, interfacial heat transfer) in the quench front and froth region using a fine moving mesh. The source terms are passed to the COBRA-TF part to solve the problem on the coarse Eulerian mesh.

As a final note, time smoothing, void ramps and other numerical techniques are eliminated form the FHMG module. This was achieved by using the fully-implicit scheme and by choosing a more physical approach to resolve the transition from different flow regimes.

\section{ANALYSIS OF A FORCED REFLOOD TEST}

A preliminary assessment of the new reflood model was carried out against the FLECHT-SEASET forced reflood experiments [10] [11]. The FLECHT-SEASET (Full Length Emergency Core Heat Transfer - System Effects And Separate Effect Tests) test program was performed during the 1980s to simulate the reflood in a typical PWR geometry. The test facility is a full-length 161-rod bundle, which has the same geometry, rod diameter and pitch, of a typical Westinghouse PWR core with $17 \times 17$ fuel rod arrays.

The test facility was model with COBRA-TF/FHMG computer code. The selected test is a forced reflood with 2.5 $\mathrm{cm} / \mathrm{sec}$ flooding rate. The original COBRA-TF and the new 
COBRA-TF/FHMG are used to simulate one of the reflood test and code predictions are compared with the test data.

The noding scheme used to model the FLECHT-SEASET test bundle is based on one-dimensional single-channel model of the test bundle. The coarse Eulerian mesh include 14 nodes in the heated section. Additional nodes are added at the bottom and at the top of the test bundle to model the lower and upper plenums respectively. The heated section of the bundle contains 8 spacer grids, spaced $0.56 \mathrm{~m}$ apart. The axial mesh size of the Eulerian mesh is based on two nodes per grid span.

In the experiment the reflood is initiated when the peak clad temperature reaches $1144 \mathrm{~K}(1600 \mathrm{~F})$. Subcooled liquid at $323 \mathrm{~K}$ is injected at the bottom of the test section at $2.5 \mathrm{~cm} / \mathrm{s}$. The pressure $(272 \mathrm{kPa})$ is set at the outlet of the bundle.

For this analysis the axial extension of the moving fine mesh is set equal to the axial dimension of the coarse node (26 $\mathrm{cm})$. The basis of this choice is that the axial fine mesh represents a one-dimensional sub-domain of the threedimensional coarse mesh. The coarse mesh describes the threedimensional features of the flow while the axial fine mesh is used to describe the one-dimensional problem in the region across the quench front. The fine mesh domain has been subdivided in 10 nodes, such that each node has a length of approximately 2.6 $\mathrm{cm}$.

Figure 2 shows the predicted clad at the elevation of $1.93 \mathrm{~m}$ as well as the measured data. This is the elevation where the Peak Clad Temperature (PCT) is reached. The clad temperature is under-predicted by the code during the first 200 seconds. The clad temperature drops very quickly when the rod is quenched. Figure 2 shows that the quench of the rod is delayed of about 100 seconds. The vapor temperature at the same elevation is also under-predicted by the code (Figure 3). The integral of the entrainment flow rate calculated at the mid-plane elevation and at the outlet of the bundle is shown in Figure 6 together with the measured value at the exit of the test section. The entrainment flow rate at the exit of the channel is in good agreement with the data.

The under-estimation of the clad temperature and the vapor temperature is an indication that the interfacial heat transfer between the entrained droplets and the vapor is over estimated in the film boiling region. Sensitivity studies showed that the major contributor to the overestimation of the heat transfer is an over-estimation of the entrainment rate at quench front.

The entrainment rate is in agreement with the test data at the exit of the bundle where the measurement is available. However the entrainment rate at the quench front can be only inferred, therefore it is possible that the entrainment rate is overestimated at the quench front and froth region where droplets are generated. In fact the evaporation of the droplets and the subsequent vapor de-superheating are major contributors to the heat transfer during the dispersed flow film boiling. The calculation shows that the entrainment flow rate that reaches the top of the bundle is $40 \%$ of the value at the generation point. The predicted vapor temperature is in better agreement with the test data at higher elevations. The velocity at which the quench front advances in the test section is slightly underestimated by the code (Figure 5). All these results provide and indication that the entrainment rate at the quench front is over-estimated. This conclusion has been confirmed by sensitivity studies where the source of entrainment at the quench front was artificially increased.

The entrainment in the original version of the code is determined by the combined effect of interfacial drag model, heat transfer mode logic and flow regime switches. When the mesh size is much larger than the actual space scale of the phenomena of interest the lumping effect becomes important. As a result the effect of the node size is important in determining the average void fraction and the flow regime. In other words the node size becomes an important parameter of the model itself. Individual effect that contributes to the entrainment cannot be separated and assessed since the individual models are tightly coupled. On the contrary, the use of local fine mesh at the quench front allows us to resolve the local conditions in details and the effect of the node size becomes less important.

Current models do not account directly of the evolution of the droplet from the generation point where a strong mechanical non-equilibrium can exist to the bundle exit. The droplet size at the generation point is basically deduced from observations further downstream. The mechanism of entrainment is only postulated and based on separate experiments, often obtained with different geometry and thermal-hydraulic conditions respect to the prototypical core conditions

The current implementation of the models in the fine mesh is a simple extrapolation of previous models developed for a relatively coarse mesh. Threfore it is not surprisingly that current results are quantitatively biased. On the other hand, the effect of the fine mesh has already significant advantages. A more continuous source of entrainment in the node in proximity of the quench front is predicted. The comparison with the previous version of the code based on a coarse Eulerian mesh shows that the entrainment process does not depend on the mesh size or on the position of the quench front relatively to the cell boundaries. This is a more realistic behavior and is closer to the observations.

A similar mesh size was attempted using the original version of the code (COBRA-TF). However the computation time became extremely large and more important the calculation was very unstable and often leading to divergence. In other words the same spatial resolution cannot be achieved or it is practicable with the current coarse mesh version of COBRA-TF.

The FHMG module provides some detailed information about the structure of the quench front and froth region. The clad temperature axial distribution is shown in Figure 6. The quench front is located at the center of the fine mesh where the rod temperature is subjected to a large axial variation. The region below the quench front is in sub-cooled boiling regime and the region above the quench front is in transition boiling 
regime. The region above the quench front represents the froth region and is the region where droplets are entrained.

The void fraction distribution is shown in Figure 7. The void fraction is low in the sub-cooled boiling region, and then increases significantly in the proximity of the quench front where the stored energy is released and a significant amount of vapor is locally generated. The calculation shows that the void fraction temporary decreases just above the quench front and then increases above 0.8 in the following nodes. The local void fraction decrease, in the control volumes just above the quench front, is due to the continuous liquid that is displaced from the quench front by the large amount of vapor generated at the quench front. The void fraction decreases again at the top of the froth region. This is because the code predicts that some of the entrained droplets are suspended at the top of the froth region. The entrainment process is occurring at the bottom of the froth region in the two or three control volumes located downstream the quench front where the continuous liquid is collected.

Note that the picture of the quench front and froth region described above represents a snap shot (at $\mathrm{t}=100$ seconds) and the all process is dynamic and unsteady. However a similar pattern is observed at other instants during the reflood transient as the fine mesh moves into the channel following the quench front.

These results are limited by the current status of the entrainment model, which is a simple adaptation of the previous COBRA-TF model. The current entrainment model was not developed considering the use of a fine mesh and it can lead to unphysical results. The current entrainment model was taken directly from the original version of COBRA-TF and was based on the Kataoka Ishii model [12]. In their work, Kataoka and Ishii [12] suggested that the entrainment is locally a function the superficial gas velocity and the distance from the top of a mixture level. Several entrainment regimes are possible at various elevations in the froth region. The model predicts liquid flow rate in the form of droplets emerging from the top of the froth region. In other words the entrainment flow rate calculated by the model is already the result of the integral effect of all the processes occurring in the froth region. The entrainment rate is the result of the combined effect of the amount of liquid entrainment above the mixture level, the droplet breakup and the emerging droplet size distribution, the forces applied to the droplets (gravity and interfacial drag), the acceleration of the droplets and the deposition of droplets.

The entrainment rate predicted COBRA-TF was assessed against the FLECHT-SEASET data. Since the mesh used was relatively coarse, the use of a model based on the end results of the Kataoka-Ishii model was justified. Note that, in this case the node size is an essential parameter of the model itself.

On the other hand, a fine mesh has the advantage that these individual effects can be separated. In principle, a mechanistic entrainment model, which is finally independent on the mesh size, can be developed solving the problem with the fine mesh. In fact the results showed that the FHMG provides a detailed solution for the flow in the froth region and can incorporate directly physical entrainment models. Nevertheless the assessment of these physical details require more measurements and a better characterization of the froth region.

\section{CONCLUSIONS}

A Fine Hydraulic Moving Grid Module was developed and coupled with the COBRA-TF computer code and the new version of the code has been called COBRA-TF/FHMG. The fine mesh is used in proximity of the quench front and moves in the core as the rods cool and quench. The fine moving mesh approximates the Lagrangian nature of the reflood process in the core. The new version of the code was used to simulate one of the FLECHT-SEASET test.

The analysis of the FLECHT-SEASET low flooding rate test 31504 performed with the original COBRA-TF code showed entrainment oscillations, which were not observed in the experiment.

Noding sensitivity studies indicated that key thermalhydraulic phenomena during reflood can be node size dependent. The effect of the void ramps, time-smoothing techniques, switches between different flow regimes and heat transfer modes are often tailored and validated for a relatively small range of conditions and node size ranges. This 'fine tuning' become cumbersome and presents uncertainty when the flow conditions experience sharp spatial discontinuities such as in the quench front and froth region.

The COBRA-TF/FHMG predictions are still biased respect to the observations and further assessment is necessary. For instance, the clad and vapor temperature are underestimated by the code while the entrainment rate at the quench front and the interfacial heat transfer in the film boiling region is overestimated. On the other hand, the quench front velocity, which was underestimated by the previous version of the code, is now in good agreement.

The calculations with the COBRA-TF/FHMG showed qualitatively significant improvements. The fine hydraulic mesh, which is used in proximity of the quench front, provides a more detailed void fraction distribution in the quench front and froth region. Results appear to be almost insensitive to the size of the fine moving mesh. Void ramps, time smoothing techniques were eliminated.

The current implementation of the models used at the fine mesh level is a simple 'extrapolation' of previous models, which were developed for the original version of the code. As more data becomes available that better characterizes the phenomena at the quench front and froth region, improved models can be developed and implemented in the FHMG module to solve the thermal-hydraulic problem of the quench front at a more fundamental level. This task requires both analytical work as well as experimental work. Experimental work is necessary to better characterize the flow regime and heat transfer in the froth region. 
From a computational point of view, the FHMG can represent a significant overhead during the solution process of COBRA-TF/FHMG since for every time step on the coarse Eulerian mesh the code needs to calculate the solution on the fine moving mesh. Typically, with the current configuration, the COBRA-TF runs a reflood transient 2-3 times faster than the COBRA-TF/FHMG with the same coarse Eulerian mesh. However with COBRA-TF/FHMG, by having a fine mesh at the across the quench front, the precision of the solution can be substantially increased and better models can be developed. The time step size used by the COBRA-TF/FHMG code is limited by the COBRA-TF side, which is based on the semiimplicit scheme. Since the fine mesh is based on a fully-implicit scheme, the time step size used to solve the flow on the fine mesh is similar to the time step used on the coarse mesh.

Results showed that the COBRA-TF/FHMG is able to handle a mesh size which in the quench front and froth region can be as low as $1.0 \mathrm{~cm}$. COBRA-TF alone becomes numerically unstable to make the solution impracticable when the mesh size is less than $2-3 \mathrm{~cm}$.

Compared to the semi-implicit scheme, the use of a fullyimplicit scheme in the FHMG Module has also the advantage that void ramps, time-smoothing, Courant limits and other numerical techniques are not required to achieve a stable solution. A stable solution can be achieved on a fine mesh with a relatively large time step size (of the order of 0.01 seconds). Also parametric studies showed that the solution obtained with the fully-implicit scheme is smoother and the oscillations observed using COBRA-TF are partially eliminated.

The fine hydraulic mesh which has been developed need to be considered as the first step for reflood model improvements and represents a good framework for further development. More detailed models can be developed specifically for the quench front and froth region and included in the FHMG module.

\section{ACKNOWLEDGMENTS}

The work presented in this thesis was possible thanks to the financial support from the U.S. Nuclear Regulatory Commission.

\section{REFERENCES}

1. Schnurr, N., et al: "TRAC-PF1/MOD2 User's Guide," Nuclear Technology and Engineering Division, Engineering Safety Analysis Group N-6, Los Alamos National Laboratory (November 1990).
2. The RELAP5 Code Development Team, "RELAP5/MOD3 Code Manual Volume V: Models and Correlation", NUREG/CR-5535, June 1995.

3. Paik, C.Y., Hochreiter, L.E., Kelly, J.M. and R.J. Kohrt, "Analysis of FLECHT-SEASET 163-Rod Blocked Bundle Data using COBRA-TF," NUREG/CR-4166, (1985).

4. Thurgood, M.J, George, M.J.: "COBRA/TRAC - A ThermalHydraulic Code for Transient Analysis of Nuclear Reactor Vessels and Primary Coolant System” NUREG/CR-3046 Vol. 1-4, March 1983.

5. Barre, F., Boudier, P., Parent, M. et al., "New Developments in the CATHARE 2 Code." - STR/LML/EM/94-210, Feb. 94

6. Bartak, J., Janicot, A. - "Developments in Reflood Modelling" - SMTH/LMDS/EM/97-005, June 1997

7. Barre, F. - "Reflooding Model of CATHARE 2 V1.2E Code: PSCHIT Module" - STR/LML/EM/91-16, Dec. 1991.

8. Yadigaroglu, G., Nelson, R.A., Teschendorff, V., Murau, Y., Kelly, J., Bestion, D. - "Modelling of Reflooding". Publication Nuclear Engineering and Design 145 (1993) 135.

9. Frepoli, C., Hochreiter, L.E., Mahaffy, J., Cheung, F.B. - “A Noding Sensitivity Analysis using COBRA-TF and the effect of spacer grids during core reflood" - Proceedings of ICONE $8,8^{\text {th }}$ International Conference on Nuclear Engineering - April 2-6, 2000, Baltimore (USA).

10. Lee, N., Wong, S., Yeh, H.C. and L.E. Hochreiter, "PWR FLECHT-SEASET Unblocked Bundle Forced and Gravity Reflood Task Data Evaluation and Analysis Report," NUREG/CR-2256, (1981).

11. Loftus, M.J., et al., "PWR FLECHT-SEASET Unblocked Bundle Forced and Gravity Reflood Task Data Report," NUREG/CR-1532, (1980).

12. Kataoka, I. and Ishii, M. - Mechanistic Modeling and Correlations for Pool Entrainment Phenomenon - NUREG/CR-3304, (1983).

13. Tannehill, J.C., Anderson, D.A., Pletcher, R.H. Computational Fluid Mechanics and Heat Transfer - Taylor\&Francis (1997)

14. Golub, G., Ortega, J.M. - $\underline{\text { Scientific Computing, An }}$ Introduction With Parallel Computing - Academic Press, Inc. (1993) 


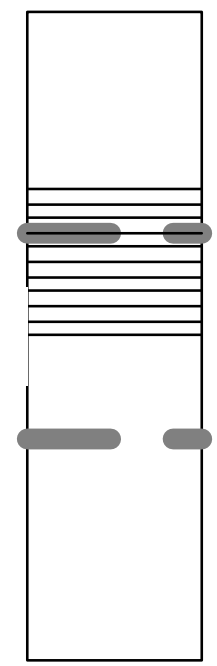

$\mathrm{t}$

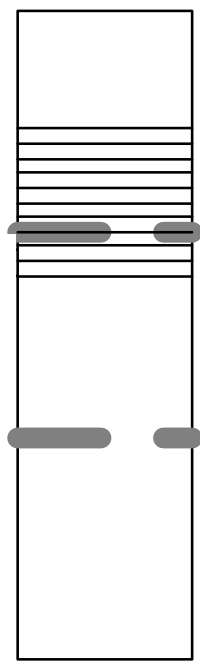

$\mathrm{t}+\Delta \mathrm{t}$
Figure 1 - The Moving Fine Hydraulic Grid

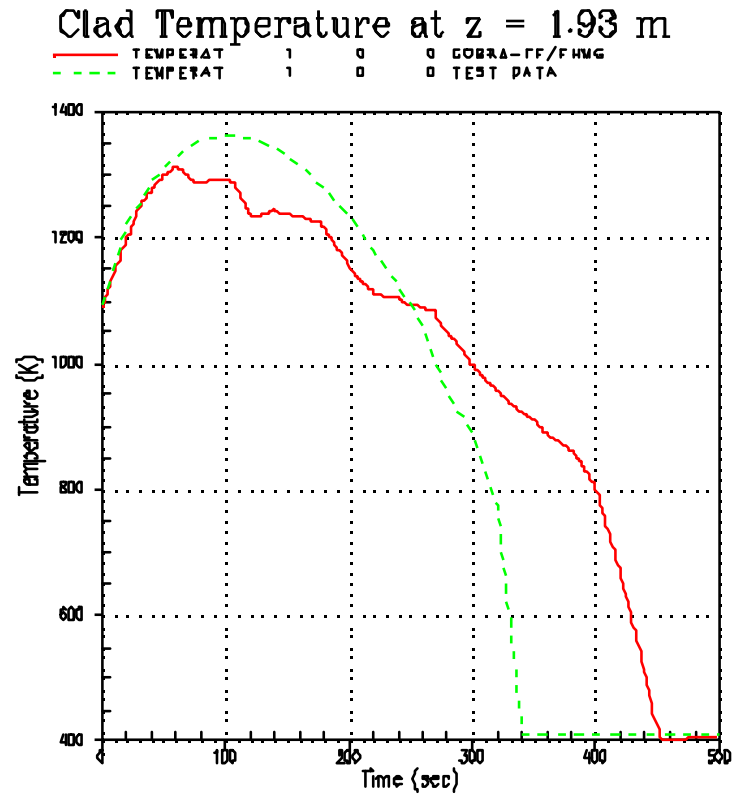

Figure 2-Clad temperature

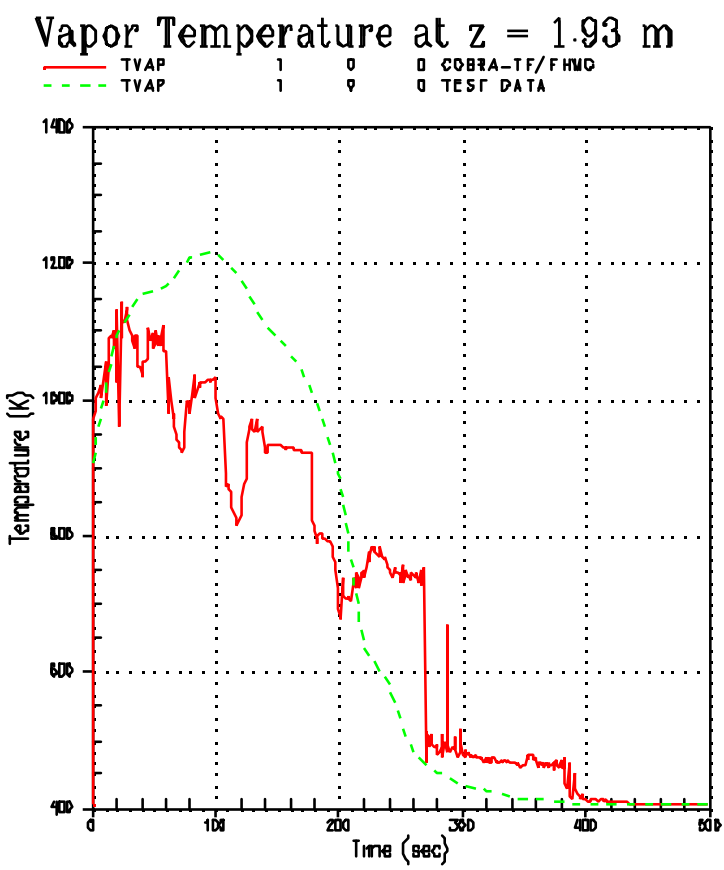

Figure 3 - Vapor Temperature

Entrainment Flowrate (Integral)
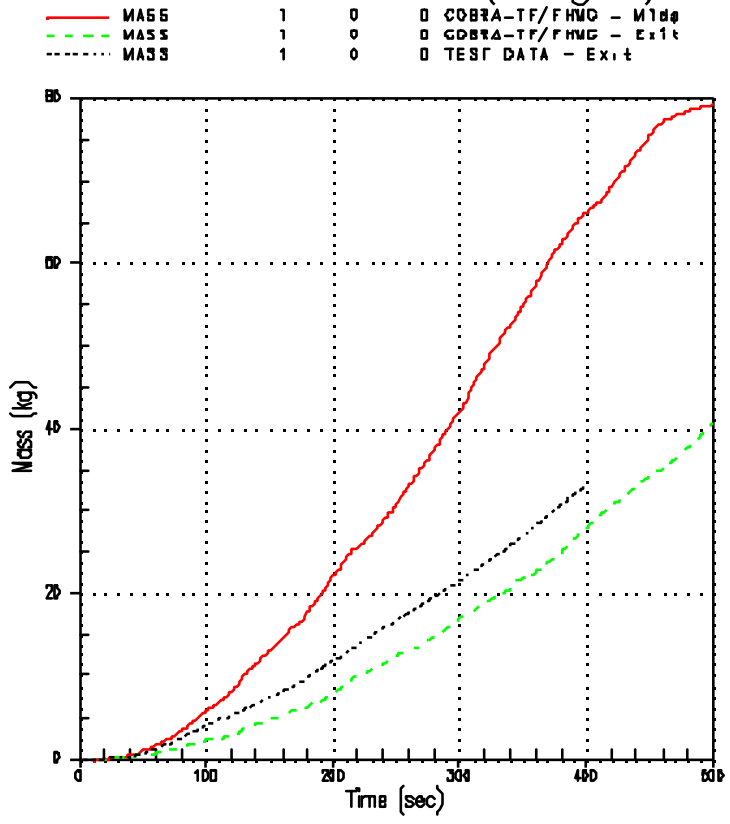

Figure 4 - Entrainment Flow Rate 


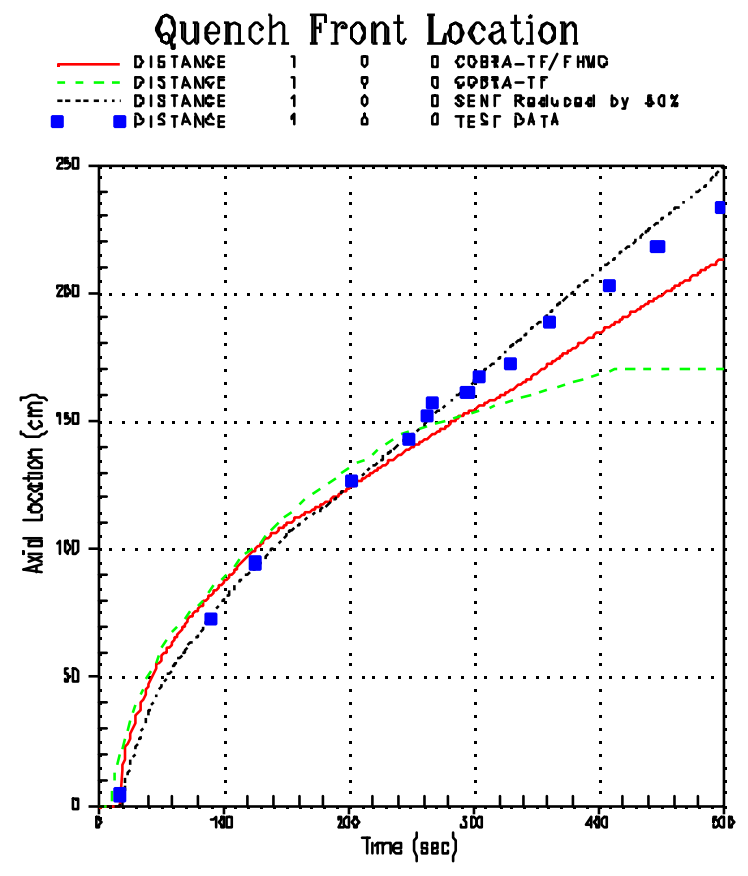

Figure 5 - Quench Front Location

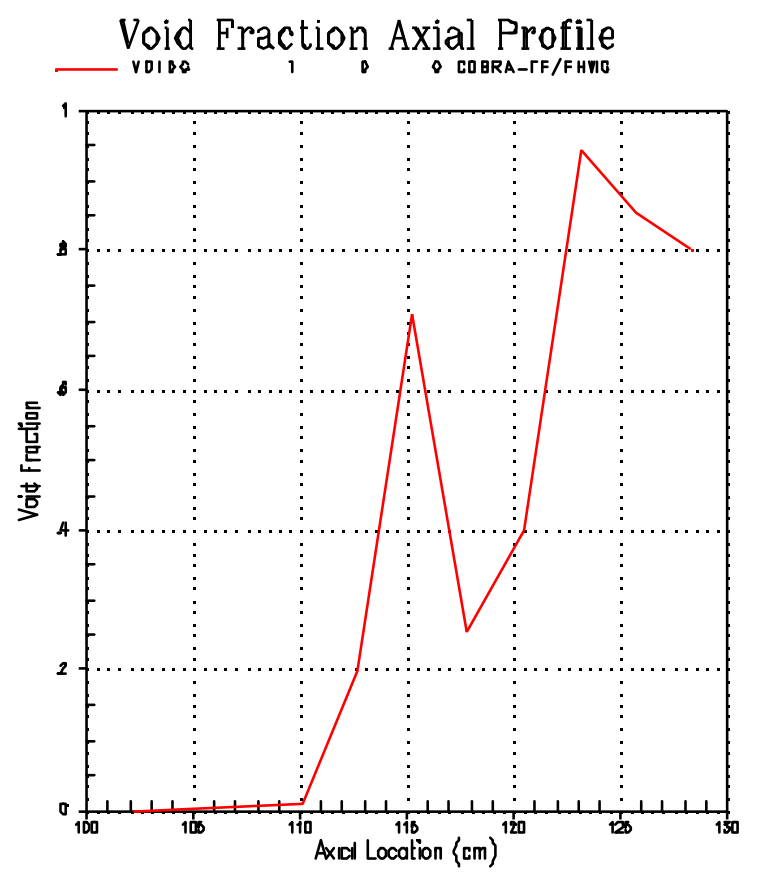

Figure 6 - Void Fraction Axial Profile in Proximity of the Quench Front

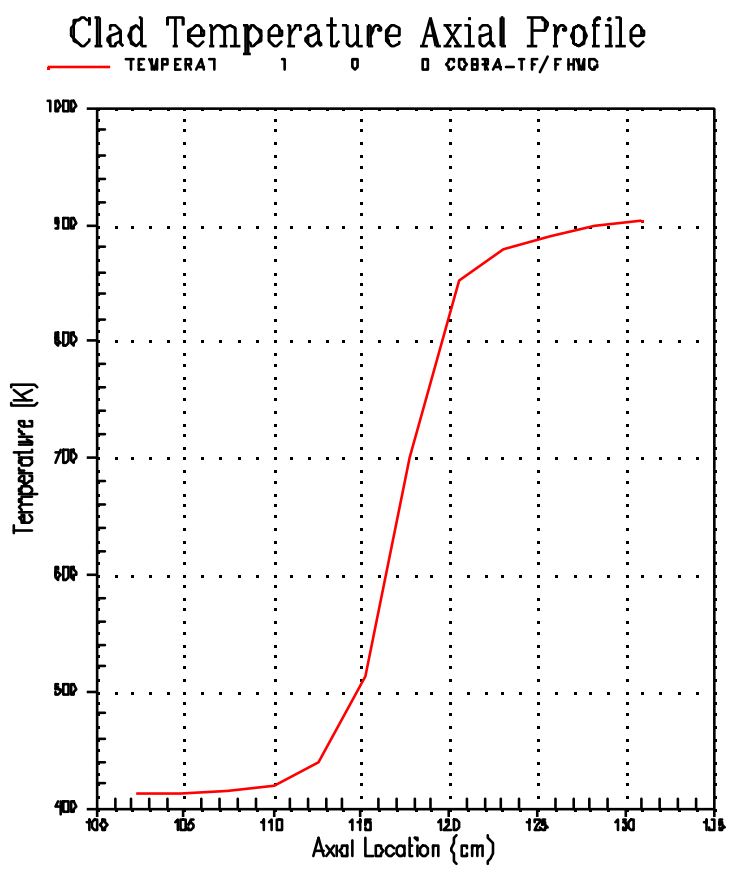

Figure 7 - Void Fraction Axial Profile in Proximity of the Quench Front 